\title{
DIET AND ANAEMIA
}

$\mathrm{T}$ $\mathrm{HE}$ hundredth meeting of the Nutrition Society, held at the Medical College, London Hospital, on March 10, took the form of a symposium on "Diet and Anæmia", which some 118 members and guests attended. The chair was taken by Sir Stanley Davidson, who in a brief introduction referred to the improvement in the clinical picture which has been effected by better medical education and treatment based on much research, culminating in the discovery of vitamin $\mathrm{B}_{12}$.

The morning session was devoted mainly to the causes of anæmia. The first paper, by Dr. G. R. Wadsworth and Prof. B. S. Platt (London School of Hygiene and Tropical Medicine), was entitled "Zymotic and Other Factors in the Development of Anæmia" and dealt especially with factors affecting the protein economy in its relation to the development of anæmia. About $6 \mathrm{gm}$. of globin from hæmoglobin is recycled daily, or about a tenth of the estimated total daily protein requirement. If the breakdown products of globin are not returned to the metabolic pool, anæmia may develop if there is deficient protein intake or lack of specific hæmatinic sub. stances such as vitamin $B_{12}$ or folic acid. However, the formation of hæmoglobin takes precedence over that of all other body proteins, even of serum protein; hence deficiency of hæmoglobin may not become evident for a long time, and then will be more readily detected by a fall in the total amount of hæmoglobin in the body rather than by a fall in hæmoglobin concentration in the blood, according to recent findings by Hallgren. Feeding experiments with glycine labelled with nitrogen-15 or with carbon-14 support the view that hæmoglobin may be partly derived from stroma protein and may be synthesized, while the maturing red cell is in cir. culation, from substances derived from the plasma. Severe anæmia may develop in infections (for example, meningitis) when iron therapy may be of value, in infestations (for example, malaria, hookworm) and following severe burns.

The second paper, by Prof. A. W. Woodruff (London School of Hygiene and Tropical Medicine), dealt with anæmia due to malnutrition in the tropics and mentioned the high maternal mortality-rates in Indian cities. Some nutritional megaloblastic anæmias may be due to deficiency of the Wills factor, which may be distinct from folic acid and vitamin $B_{12}$. Anæmia due to protein malnutrition may be macronormoblastic, with fibrosis of liver and fatty infiltration, the erythrocytes often being broader and thinner than normal. In the tropics, this type of anæmia can be more serious than megaloblastic and other nutritional anæmias.

The third paper, by Dr. P. B. B. Gatenby, of the Rotunda Hospital, Dublin, dealt with anæmia of pregnancy, which has been investigated there since the beginning of 1953. A special study in 1953 of four hundred cases of severe iron-deficiency anæmia (hæmoglobin less than $9 \mathrm{gm}$. per $100 \mathrm{ml}$.) showed half of them to have seldom or never eaten meat or other animal food such as eggs. Iron therapy corrects the anæmia and often prevents relapse to the iron-deficient state before the next pregnancy. In the absence of iron therapy, the incidence of the anæmia increases with the number of pregnancies and with the lowered dietary intakes of iron and vitamin C. In twenty- eight cases of megaloblastic anæmia in which a particular note was taken of the diet, twelve were eating very little meat or eggs, and another eight lacked protein foods, while the remaining eight had an apparently normal diet. Almost all the cases of iron-deficiency anæmia respond to folic acid and some to massive doses of vitamin $B_{12}$.

In the subsequent discussion, Dr. Lucy Wills expressed the opinion that macronormoblastic anæmia of pregnancy such as was encountered by Prof. Woodruff in Nigeria is an intermediate stage, developing later into megaloblastic anæmia. Prof. Woodruff in his reply suggested that this state of affairs may be due to a deficiency of vitamin $\mathrm{B}_{12}$ or of folic acid combined with a protein deficiency.

In the afternoon session, Dr. G. H. Spray (Nuffield Department of Clinical Medicine, Oxford) read a paper on "The Role of Pteroyl Glutamic Acid and Related Compounds in Macrocytic Anæmia". The history of the problem since Wills's work in 1931 was first briefly reviewed. The limited effectiveness of yeast extracts such as 'Marmite' in the treatment of pernicious anæmia may be due to their content of folic acid, although the possible existence of an unidentified 'Wills factor' is not yet entirely ruled out. A normal serum vitamin $\mathbf{B}_{12}$ in megaloblastic anæmia is generally taken to indicate a deficiency of folic acid, for which there is no simple test yet available. A hæmopoietic response to folic acid is usually assumed to indicate a disturbance in the metabolism of this factor, which may be due to dietary deficiency (for example, nutritional macrocytic anæmia in India and Africa), defective absorption (in tropical sprue and idiopathic steatorrhoea) or excessive demands, as in pernicious anæmia of pregnancy. In India, Africa and the southern United States, nutritional macrocytic anæmia occurs which is associated with low intakes of fresh fruit and green vegetables and is corrected by oral administration of folic acid. If there is also a very low intake of animal protein, vitamin $\mathbf{B}_{12}$ deficiency may be encountered. Anæmia in cases of epilepsy may be due to the use of phenytoin, a possible antagonist to folic acid.

Vilter and his colleagues suggest that folic acid and vitamin $B_{12}$ take part in reactions leading to the synthesis of the nucleoproteins of blood cells from simple precursors. In the absence of vitamin $\mathbf{B}_{12}$ there is an excessive demand for folic acid, which keeps the reactions going by 'mass action', and it may eventually become deficient. Large doses of folic acid increase blood formation, using up the romaining small stores of vitamin $B_{12}$ and causing exacerbation of the nervous degeneration. In patients with pernicious anæmia, there may be eventually hæmatological relapse. This useful working hypothesis does not explain completely the role of folic acid in blood formation, its utilization from the diet, its storage and excretion, and the question as to the utilization of folic acid synthesized by intestinal bacteria still remains unanswered.

The second paper in the afternoon session was by Dr. J. R. Evans (Nuffield Department of Clinical Medicine, Oxford) and dealt with the absorption of vitamin $\mathrm{B}_{12}$ in the megaloblastic anæmias. Vitamin $B_{12}$ labelled with cobalt- 60 was used, and the radioactivity of the fæces was measured after an oral dose of 0.5 ugm., the assumption being made that, all 
radioactivity not recovered in the fæces had been absorbed. In forty-four observations on thirty-five control subjects, the radioactivity in the fæces ranged from 9 to 47 per cent and averaged $27 \cdot 3 \pm 1 \cdot 6$ per cent of that present in the oral dose. In twenty-four pernicious anæmia patients, the corresponding average percentage was $92 \cdot 3 \pm 1 \cdot 3$. When these patients were given intrinsic factor, most of the results were within the limits observed in normal subjects. Achylia and atrophy of the gastric mucosa supported these findings in each of nineteen of the patients who were studied. Sterilization of the bowel with chlortetracyclene did not increase the uptake of labelled vitamin $B_{12}$ in a patient with untreated pernicious anæmia. Studies on megaloblastic anæmia following gastric surgery showed that, after total gastrectomy, little or no labelled vitamin $B_{12}$ is absorbed unless intrinsic factor is given with it. In five patients with partial gastrectomy, failure of absorption was corrected by intrinsic factor, while in another nine patients in whom no megaloblastic anæmia developed after removal of the distal half of the stomach, there was no permanent impairment of vitamin $B_{12}$ absorption. In seven patients with idiopathic steatorrhoea and megaloblastic anæmia, absorption was normal in one young patient, slightly impaired in another and negligible in the remaining five. Intrinsic factor seldom caused improvement, even when given in very large doses. In another four patients with idiopathic steatorrhœa, but no megaloblastic anæmia, absorption was normal in three, and only slightly reduced in the fourth. Absorption was unaffected in megaloblastic anæmia of pregnancy or the puerperium and in megaloblastic anæmia associated with epilepsy.

The final paper, by Dr. F. Wokes (Ovaltine Research Laboratories, King's Langley), described anæmia associated with dietary deficiency of vitamin $B_{12}$ encountered in a group of about a hundred and fifty persons termed 'vogans' who consume no animal food whatever. There was no megaloblastic or macrocytic anæmia, but in rather less than half the subjects there were low serum $B_{12}$ levels (less than $100 \mu \mu \mathrm{gm} . / \mathrm{ml}$.) accompanied by neurological manifestations ranging from slight paræsthesia to subacute combined degeneration of the cord. The wide variation in response was probably not due to variations in dietary intake of the vitamin, which was not found in significant amounts in the foods consumed by the 'vegans'. It was thought to be more likely to be caused by differences in the degree of intestinal synthesis of the vitamin.

Study of the 'vegan' diet showed its vitamin content to be satisfactory, apart from $B_{12}$ and possibly also $\mathrm{D}$. The average protein intake was rather low (9-11 per cent on the calorie basis), and the large amounts of pulses consumed tended to lead to a deficiency of methionine, which would be aggravated by the deficiency of vitamin $\mathbf{B}_{12}$. This, together with the unusually high intakes of folic acid from green vegetables, may have been responsible for the neurological manifestations.

The part played by vitamin $\mathrm{B}_{12}$ in the de novo synthesis of labile methyl groups to convert homocysteine to methionine, and also in the reduction of disulphide to sulphydryl groups, has led to a study in 'vegans' and non-'vegans' of the metabolism of thiocyanate, the sulphur-containing detoxification product of cyanide, in the metabolism of which vitamin $B_{12}$ in the form of hydroxo- or aquocobalamin appears to be implicated. A sulphur transfer cycle was described for synthesis of essential sulphurcontaining metabolites which might include the methionine deficient in 'vegan' diets. Lack of vitamin $\mathbf{B}_{12}$ might also, by inhibition of a sulphydryl system, lead to abnormal metabolism of tryptophan and tyrosine, with accumulation of toxic products, which might be responsible for the neurological manifestations.

In the subsequent discussion, Dr. C. C. Ungley described scotomata occurring in one of the 'vegans', which were cured by prolonged administration of vitamin $\mathrm{B}_{12}$.

\section{VEGETABLE TANNINS SYMPOSIUM IN CAMBRIDGE}

$T$ 'HE Society of Leather Trades' Chemists held a symposium on "Vegetable Tannins" during April 12-13 in the Chemistry Department, University of Cambridge, at which more than a hundred members and guests participated.

After the symposium had been opened by the president of the Society, Dr. R. G. Mitton (British Leather Manufacturers' Research Association), the chairman, Prof. R. D. Haworth (Chemistry Department, University of Sheffield), briefly referred to Emil Fischer's outstanding contribution to the chemistry of the gallotannins and mentioned how the early optimistic attempts of the 1920's to bring order to the untidy field of tannin chemistry was not realized. The reason for this is that those physical methods, which are now used for the isolation of single substances, were unknown. As a result of recent work, much of which, said Prof. Haworth, has been carried out by those present at the symposium, order and interest have been restored. Considerable academic and technical research is now in progress, and we have learned much concerning the units from which the complex tannins are composed.

In an introductory paper, on the scope of vegetable tannin chemistry, Dr. T. White (Forestal Central Laboratories) treated historically the chemistry of the tannin and related polyphenol constituents of the principal vegetable tannin extracts. $H_{\Theta}$ dealt with the previously proposed classification of tannin extracts, defined a tannin (as opposed to a polyphenol) and directed attention to tannin action. New work on the degradation of the major constituent of commercial gallotannin was outlined. The preliminary results can be interpreted in terms of a trisaccharide formula which is reminiscent of the tetrasaccharide formula proposed this year for sumach gallotannin by Grassmann and co-workers. Dr. White stressed that the condensed tannins cannot now be considered as a single class of compound. His paper included a review of the physical chemistry of gross tannin extracts, and a provocative account of the physiological function of tannins in the intact plant, notably as inactivating agents for vectortransmitted virus proteins.

Mr. H. G. C. King (also of the Forestal Central Laboratories) and Dr. White then gave a paper on quantitative determination of specific nuclei and components of vegetable tannin extracts. In the same way that paper chromatograms may be used for the separation of tannin constituents, they may also form the basis for the estimation of these substances, when used in conjunction with specific 